\title{
Multiplex real-time PCR assay for detection of respiratory pathogens among pneumonia affected children
}

\author{
Kohinoor Akter Raton, Md. Asif Hossain, Rashed Noor* \\ Department of Microbiology, Stamford University Bangladesh, 51 Siddeswari Road, Dhaka 1217, Bangladesh
}

\section{Email address:}

noor.rashed@yahoo.com (R. Noor)

\section{To cite this article:}

Kohinoor Akter Raton, Md. Asif Hossain, Rashed Noor. Multiplex Real-Time PCR Assay for Detection of Respiratory Pathogens among Pneumonia Affected Children. American Journal of Biomedical and Life Sciences. Vol. 1, No. 3, 2013, pp. 53-57.

doi: $10.11648 /$ j.ajbls.20130103.13

\begin{abstract}
Molecular diagnostic methods offer a rapid and more sensitive strategy with high selectivity compared to the traditional immunoassays and culture techniques. Present study attempted to employ the molecular approach for the diagnosis of respiratory viral- and bacterial infections among the pneumonia infected children in Dhaka Metropolis. Samples were aseptically collected, processed and analyzed by using Multiplex Real Time PCR technique to detect respiratory pathogens within a time frame of February 2013-June 2013. Influenza viruses, human meta-pneumo viruses, respiratory syncytial viruses and other potential infective viruses were diagnosed. Among the infective bacterial population, presence of Mycoplasma pneumoniae, Chlamydia pneumoniae, Streptococcus pneumoniae, Staphylococcus aureus, Klebsiella pneumoniae, Legionella species, Salmonella species were detected. Among the nasopharyngeal and orpharyngeal (NPOP) samples, Influenza B and Streptococcus pneumoniae were found to be dominating (34.8\% and $30.4 \%$, respectively) whereas the induced sputum (IS) samples were $100 \%$ positive for S. pneumoniae followed by around $50 \%$ prevalence with equine arteritis virus, para influenza virus and the respiratory syncytial viruses A and B. Considering the spatial identification of an array of microorganisms, results of the current study sufficiently may endorse such molecular method of diagnosis for the betterment of public health.
\end{abstract}

Keywords: Respiratory Pathogens, Pneumonia, Molecular Diagnostic Methods, Public Health

\section{Introduction}

Acute respiratory tract infections have long been known to be the leading cause of hospitalization of infants and young children in developing countries with a subsequent impact on children death [1-3]. Pneumonia, an infection of the lungs, is a serious illness with significant morbidity and mortality rates. A wide range of microorganisms may trigger pneumonia in children as well as in adults; however, the exact etiology in $20-50 \%$ cases has not yet been established [4,5]. Around 20\% Bangladeshi children $(<2$ years) with respiratory infection unfortunately can not avail any health care services [6]. Furthermore, malnutrition, overcrowding and lack of access to health care may contribute to the increased mortality [7,8]. Therefore, easy, accurate and rapid molecular diagnosis of a broad range of respiratory pathogens are in demand alternative to the conventional culture methods which often leads to false negative results.

Interestingly, the prevalence of pneumonia is concentrated in India, China, Pakistan, Bangladesh, Indonesia and Nigeria where $44 \%$ of the world's children aged less than 5 years live [9-14]. Along with other infectious diseases, pneumonia stands as the trigger of death among children in low income countries [11,15-20]. However, limited information is available on the severity of risk factors associated with pneumonia among young children in this region. Besides, lack of sufficient knowledge on the molecular diagnostic strategy may interrupt the precise method development.

For the past two decades, molecular diagnostic techniques for the detection of respiratory pathogens over the conventional culture techniques have developed globally, providing rapid results with an increased sensitivity [11, 21-23]. Among them, the multiplex real-time PCR has been shown to be more sensitive and specific, yielding results within 6 hours and enabling the direct detection of viruses which is impossible only be employing the culture methods [24-26].

Along these lines, present study attempted to estimate the incidence of pneumonia and detection of causative 
agents of this disease in the developing countries like Bangladesh.

\section{Materials and Methods}

\subsection{Sampling}

Respiratory samples including nasopharyngeal (NP), orpharyngeal (OP) and induced sputum (IS) were collected, processed and analyzed during February 2013-June 2013. Two nasopharyngeal (NP) specimens were collected from each of the pneumonia infected children. One NP flocked swab was collected placed into viral transport medium, and a second NP Dacron or rayon swab was placed in skim milk tryptone - glucose-glycerin (STGG) medium. Orpharyngeal (OP) Dacron or rayon swab was collected and placed into the same vial as the NP flocked swab. The OP swab was taken by touching the swab to the posterior oropharynx and rubbing for 1-3 seconds. One $\mathrm{ml}$ of induced sputum was collected from all patients within 24 hours except those with contraindications, which include the following: hypoxia ( $<92 \%$ on supplemental oxygen), inability to protect airways, and severe bronchospasm at admission in hospital. Metered Dose Inhalers (MDIs) was used for bronchodilation. Light chest percussion was employed in children $<2$ years to improve mobilization of sputum. In children $\geq 2$ years, mobilized sputum was collected by induction with nebulization of normal saline. The quality of the specimen was assessed by using the "Bartlett's Score". All samples were stored at $-20 \quad \mathrm{C}$ until extraction.

\subsection{Preliminary Extraction of Nucleic Acid with EasyMag (BioMérieux) and Selection of Primer/Probe}

One negative control (NC) and one internal control (IC) was taken from the refrigerator and kept in the normal temperature for some minutes. All the organisms described in table 1 were used as positive and negative controls. For example, PC fluAB_RHPPmix =Master mix and positive control, NC fluAB_RHPPmix $=$ Master mix and negative control. All the PC $\&$ NC were free from extracted samples. Positive controls were not extracted. Equine arteritis virus was used as an internal control (IC), which was introduced into the lysis buffer at the extraction stage of each sample and the negative control. Before use, reagents were thawed and homogeneously mixed. Patient samples and the NC were extracted by an automated nucleic acid extractor (NucliSENS ${ }^{\text {TM }}$ EasyMAG, USA). The starting volume for the extraction was $400 \mu \mathrm{l}$ and an elution volume was $110 \mu \mathrm{l}$. Four $\mu \mathrm{l}$ of the internal controls was added to the lysis buffer of each extraction.

To perform real time PCR, different primer/ probe mix were used for pathogen detection (Table 1). In the present study, Influenza A, B and C viruses, parainfluenza viruses 1, 2, 3 and 4, coronaviruses, human meta-pneumoviruses, rhinoviruses, respiratory syncytial viruses, adenoviruses, enteroviruses, parechoviruses, bocaviruses, cytomegaloviruses, Pneumocystis jirovecii, Mycoplasma pneumoniae), Chlamydia pneumonia, Streptococcus pneumoniae, Haemophilus influenza, Staphylococcus aureus, Klebsiella pneumonia, Legionella spp., Salmonella spp. and Haemophilus influenzae were detected.

\subsubsection{Preparation of PCR with AgPath- ID ${ }^{\mathrm{TM}}$ One-Step RT-PCR Kit (Ambion $\left.{ }^{\circledR}\right)$}

FluAB_RH PP mix, Para.EAV PP mix, Cor PP mix, BoMpPfl PP mix, RsEPAcmv PP mix, Bac PP mix, KLePSa PP mix, MoBoCH PP mix, PC1_Resp33_pos plmdpool, PC2_Resp33_pos_plmd pool and the " $2 \mathrm{x}$ RT PCR buffer" of AgPath-ID ${ }^{\text {TM }}$ One-Step RT-PCR Kit were thawed for the PCR reaction. For one reaction $12.5 \mu 1$ of the “2x RT-PCR buffer" of AgPath-ID" One-Step RT-PCR Kit was homogeneously mixed with $1.5 \mu$ l PP mixes. One $\mu$ l of the "25x RT PCR enzyme mix" of AgPath-ID" ${ }^{\text {TM} O n e-S t e p ~}$ RT-PCR Kit was added to the $1.5 \mu \mathrm{l}$ PP mixes with the " $2 \mathrm{x}$ RT-PCR buffer".

Table 1. Label of information of analyzed primer/probe

\begin{tabular}{|c|c|}
\hline Label & Contents \\
\hline FluAB_RH PP & Primer/probe mix for Flu A, B \& Rhino \\
\hline Para.EAV PP & Primer/probe mix for Para 2,3, 4 \& IC-EAV \\
\hline Cor PP & Primer/probe mix for Cor 43,63, 229 \& HKU1 \\
\hline BoMpPf1 PP & $\begin{array}{l}\text { Primer/probe mix for HboV, Mpneu, Paral \& } \\
\text { HMPVA/B }\end{array}$ \\
\hline RsEPAcmv PP & Primer/probe mix for RSVA/B, CMV, AV \& EV/PV \\
\hline Bac PP & Primer/probe mix for Saur, Spneu, Cpneu \& HIB \\
\hline KLePSa PP & Primer/probe mix for Kpneu, Legio, PCP \&Salm \\
\hline МоBоСH PP & Primer/probe mix for Morax, Bord, FluC \& Haeinf \\
\hline $\begin{array}{l}\text { Resp PC1 } \\
\text { Plasmids }\end{array}$ & $\begin{array}{l}\text { For use with the yellow PPmixes 1-5 (FluA/B, Rhino, } \\
\text { Para 1/2/3/4, Cor43/ 63/ 229/ HKU, HboV, Mpneu, } \\
\text { HMPVA/B, RSVA/B, PV/EV, AV and CMV). }\end{array}$ \\
\hline $\begin{array}{l}\text { Resp PC2 } \\
\text { Plasmids }\end{array}$ & $\begin{array}{l}\text { For use with the red PPmixes } 6-8 \text { (Saur, Spneu, } \\
\text { Cpneu, HIB, Kpneu, Legio, PCP, Salm, Morax, Bord, } \\
\text { FluC and Haeinf). }\end{array}$ \\
\hline Resp NC & Negative control \\
\hline Resp IC & Internal control \\
\hline
\end{tabular}

Key: PP- primer and probe, IC- internal control, PCpositive control, NC- negative control, Flu- Influenza, ParaPara influenza virus, Cor- Corona virus, HMPV- Human meta pneumo virus, Rhino- Rhinovirus, RSV- Respiratory syncytial virus, AV- Adenovirus, EV- Enterovirus, PVParechovirus, HMPVA- Human meta-pneumoviruses, HboV- Bocavirus, CMV- Cytomegalovirus, PCPPneumocystis jirovecii, Mpneu- Mycoplasma pneumoniae, Cpneu- Chlamydia pneumoniae, Spneu- Streptococcus pneumoniae, HIB- Haemophilus influenzae type B, SaurStaphylococcus aureus, Morax- Moraxella catarrhalis:, Bord- Bordetella pertussis, Kpneu- Klebsiella pneumoniae, 
Legio- Legionella spp., Salm- Salmonella spp., HaeinfHaemophilus influenzae.

\subsection{Preparation of a 96 Well Plate for ABI 7500 (Applied Biosystems $\left.{ }^{\circledR}\right)$}

A 96 well plate (ABI 7500) was taken. For 1 reaction, 15 $\mu 1$ of the previously mentioned different PP mixes was mixed with the PCR buffer and the PCR enzyme mix in each of the wells. Ten $\mu$ of the extracted samples, the extracted negative control and the positive control (which was not extracted) was added to each mix (Each run was included with a negative and a positive control). The plate was closed with the ABI optical adhesive film, and then centrifuged.

\subsection{Programming of the Thermo Cycler}

The presence of specific viral and bacterial sequences in the reaction was detected by an increase in the fluorescence (ROX dye) observed from the relevant dual-labeled probe by the real time thermo cycler [27]. Eight different types of primer/probe mix were used to detect specific respiratory pathogens (Table 2).

Table 2. Settings of the detectors

\begin{tabular}{|c|c|c|c|c|}
\hline PP Mix & Pathogen & Reporter & $\begin{array}{c}\text { Fluorescent } \\
\text { Dye }\end{array}$ & $\begin{array}{c}\text { Detection } \\
\text { wavelengt } \\
\text { h }(\mathrm{mm})\end{array}$ \\
\hline \multirow[t]{3}{*}{ FluAB_RH PP mix } & FluA & FAM & Green & 520 \\
\hline & Rhino & VIC & Yellow & 550 \\
\hline & FluB & ROX & Orange & 610 \\
\hline \multirow[t]{4}{*}{ Para.EAV PP mix } & Para 3 & FAM & Green & 520 \\
\hline & Para 2 & VIC & Yellow & 550 \\
\hline & Para 4 & ROX & Orange & 610 \\
\hline & IC (EAV) & Cy5 & Red & 670 \\
\hline \multirow[t]{4}{*}{ Cor PP mix } & Cor 229 & FAM & Green & 520 \\
\hline & Cor 63 & YAK & Yellow & 550 \\
\hline & HKU1 & ROX & Orange & 610 \\
\hline & Cor 43 & Cy5 & Red & 670 \\
\hline \multirow{4}{*}{ BoMpPf1 PPmix } & Para 1 & FAM & Green & 520 \\
\hline & HMPV A/B & VIC & Yellow & 550 \\
\hline & $\mathrm{HBoV}$ & ROX & Orange & 610 \\
\hline & Mpneu & Cy5 & Red & 670 \\
\hline \multirow[t]{4}{*}{ RsEPAcmv PP mix } & RSVA/B & FAM & Green & 520 \\
\hline & CMV & VIC & Yellow & 550 \\
\hline & $\mathrm{EV} / \mathrm{PV}$ & ROX & Orange & 610 \\
\hline & $\mathrm{AV}$ & ATTO-647N* & Red & 670 \\
\hline \multirow[t]{4}{*}{ Bac PPmix } & S.aur & FAM & Green & 520 \\
\hline & C.pneu & VIC & Yellow & 550 \\
\hline & $\mathrm{HiB}$ & ROX & Orange & 610 \\
\hline & S.pneu & Cy5 & Red & 670 \\
\hline \multirow[t]{4}{*}{ KLePsa PPmix } & PCP & FAM & Green & 520 \\
\hline & Legio & VIC & Yellow & 550 \\
\hline & K.pneu & ROX & Orange & 610 \\
\hline & Salm & Cy5 & Red & 670 \\
\hline \multirow[t]{4}{*}{ МoBoCH PPmix } & Morax & FAM & Green & 520 \\
\hline & FluC & VIC & Yellow & 550 \\
\hline & Bord & ROX & Orange & 610 \\
\hline & Haeinf & ATTO-647N & Red & 670 \\
\hline
\end{tabular}

\section{Results and Discussion}

\subsection{Prevalence of Respiratory Pathogens}

In the present study, out of 35 cases, in 23 nasopharyngeal and orpharyngealswab (NPOP) samples, 28 pathogens were detected, while in 12 induced sputum (IS) samples, a total of 20 virus and bacteria were identified. In NPOP samples, Influenza B and S. pneumoniae possessed a relatively high frequency $(34.8 \%$ and $30.4 \%$, respectively), whereas parainfluenza viruses, human metapneumoviruses A and B, respiratory syncytial viruses $\mathrm{A}$ and $\mathrm{B}, \mathrm{S}$. aureus and Influenza $\mathrm{C}$ were found with a low frequency (Table 3). On the other hand, among the 12 IS samples, S. pneumoniae, Equine arteritis virus, Para influenza virus 1 and respiratory syncytial viruses A and B were in high frequency while influenza A , parainfluenza viruses, human metapneumoviruses A and B were found to be in a relatively low frequency (Table 3 ).

Table 3. Frequency of pathogens

\begin{tabular}{|c|c|c|c|c|}
\hline \multirow[t]{2}{*}{ Pathogens } & \multicolumn{2}{|c|}{ No. of Positive Samples } & \multicolumn{2}{|c|}{ \%Frequency } \\
\hline & NPOP & IS & NPOP & IS \\
\hline FluA & 5 & 1 & $21.7 \%$ & $8.3 \%$ \\
\hline Rhino & 3 & 0 & $13.04 \%$ & $0 \%$ \\
\hline FluB & 8 & 6 & $34.8 .0 \%$ & $50.0 \%$ \\
\hline Para 3 & 1 & 2 & $4.4 \%$ & $16.7 \%$ \\
\hline Para 2 & 2 & 1 & $8.7 \%$ & $8.3 \%$ \\
\hline Para 4 & 1 & 1 & $4.4 \%$ & $8.3 \%$ \\
\hline $\mathrm{IC}(\mathrm{EAV})$ & 3 & 7 & $13.04 \%$ & $58.3 \%$ \\
\hline Cor 229 & 3 & 0 & $13.04 \%$ & $0 \%$ \\
\hline Cor 63 & 3 & 0 & $13.04 \%$ & $0 \%$ \\
\hline HKU1 & 6 & 0 & $26.09 \%$ & $0 \%$ \\
\hline Cor 43 & 6 & 0 & $26.09 \%$ & $0 \%$ \\
\hline Para 1 & 5 & 7 & $21.7 \%$ & $58.3 \%$ \\
\hline HMPVA/B & 1 & 1 & $4.4 \%$ & $8.3 \%$ \\
\hline $\mathrm{HBoV}$ & 6 & 5 & $26.09 \%$ & $41.7 \%$ \\
\hline Mpneu & 3 & 3 & $13.4 \%$ & $25.0 \%$ \\
\hline RSVA/B & 1 & 7 & $4.4 \%$ & $58.3 \%$ \\
\hline CMV & 1 & 3 & $4.4 \%$ & $25.0 \%$ \\
\hline $\mathrm{EV} / \mathrm{PV}$ & 0 & 2 & $0 \%$ & $16.7 \%$ \\
\hline $\mathrm{AV}$ & 4 & 0 & $17.3 \%$ & $0 \%$ \\
\hline Saur & 1 & 0 & $4.4 \%$ & $0 \%$ \\
\hline Cpneu & 2 & 6 & $8.7 \%$ & $50.0 \%$ \\
\hline $\mathrm{HiB}$ & 5 & 0 & $21.7 \%$ & $0 \%$ \\
\hline Spneu & 7 & 12 & $30.4 \%$ & $100 \%$ \\
\hline PCP & 4 & 5 & $17.3 \%$ & $41.7 \%$ \\
\hline Legio & 3 & 2 & $13.04 \%$ & $16.7 \%$ \\
\hline Kpneu & 3 & 3 & $13.04 \%$ & $25.0 \%$ \\
\hline Salm & 3 & 3 & $13.04 \%$ & $25.0 \%$ \\
\hline Morax & 0 & 0 & $0 \%$ & $0 \%$ \\
\hline FluC & 1 & 0 & $4.4 \%$ & $0 \%$ \\
\hline Bord & 0 & 0 & $0 \%$ & $0 \%$ \\
\hline Haeinf & 3 & 2 & $13.04 \%$ & $16.7 \%$ \\
\hline
\end{tabular}

However, a limitation of the study may lies under the fact that several variables might hinder the adoption of such diagnostic assays based on the pathogen's DNA, rather than on its phenotype including the probable abundance of false positives and false negatives results. DNA contamination 
could take place due to the environmental condition of the experiments done, or from the utensils used to prepare the reaction mix, or from the living cell contaminations wiped out from surfaces and lab equipment.

\subsection{Implications of the Present Study}

In the present study, respiratory samples of human origin were analyzed for the detection of respiratory pathogens by the Multiplex Real Time PCR method. The identification of pathogens also helped determining the number of viruses and bacteria present in the samples. In cohort to other studies carried out so far, our results also showed the incidence of mixed infection with viruses or bacteria $[28,29]$. Onset of pneumonia with such mixed infections may occur up to $45 \%$ cases in children and $15 \%$ of infections in adults. Unfortunately, the appropriate causative agent can not be identified even in $50 \%$ cases despite careful testing [31-33]. Due to lack of the employment of sensitive methods, developing countries meet such diagnosis problems.

In Bangladesh, while an array of diagnostic research has been carried out with parasitic and opportunistic infections, and with tuberculosis, proper investigation in pneumonia diagnosis with a strategy of establishing molecular diagnostic methods is still infant [30-33]. However, the effectiveness of the molecular method lies over the sensitivity and specificity although its shortfall tickles from the cost involvement in resource poor settings.

\section{Conclusion}

In developed countries, Multiplex real-time PCR pathogen detection assays are currently being used for the detection of the presence of potentially harmful pathogens in high risk environments [34,35]. Our study imparts the ability to accurately detect a spectrum of clinically significant viruses and bacteria rapidly enough to affect patient management and initiation of infection control measures. A quantitative as well as simultaneous identification of the predominant mixed population of microorganisms including Influenza B, S. pneumoniae, equine arteritis virus, para influenza virus and the respiratory syncytial viruses $\mathrm{A}$ and $\mathrm{B}$ revealed the emerging need of the method endorsement besides the traditional diagnostic methods currently being used. However, the utilization of molecular testing, particularly highly multiplexed tests in routine patient management will depend on the cost/benefit ratio.

\section{Acknowledgements}

We thank ICDDR, B Laboratory, Knowledge for Global Life Saving Solutions, Mohakhali, Dhaka, for providing us with the facilities for the experiments described here and also grateful for the ongoing support, interest, and technical expertise of the faculty of Stamford University of Bangladesh.

\section{References}

[1] J. B. Mahony, A. Petrich, M. Smieja, "Molecular diagnosis of respiratory viral infections," Crit. Rev. Clin. Lab. Sci., vol. 48(5-6), pp. 217-249, 2011.

[2] D. K Shay, R. C. Holman, R. D. Newman, L. L. Liu, J. W. Stout and L. J. Anderson, "Bronchiolitis-associated hospitalizations among US children, 1980-1996," JAMA, vol. 282, pp. 1440-1446, 1999.

[3] M. W. Weber, E. K. Mulholland and B. M. Greenwood, "Respiratory syncytial virus infection in tropical and developing countries," Trop. Med. Int. Health, vol. 3, pp. 268-280, 1998.

[4] WHO, Legionella and the prevention of legionellosis, Geneva, Switzerland: WHO Press, 2007, pp. 120-124.

[5] J. Johnstone, S. R. Majumdar, J. D. Fox, T. J. Marrie, "Viral infection in adults hospitalized with community acquired pneumonia: prevalence, pathogens and presentation," Chest, vol. 134, pp. 1141-1148, 2008.

[6] A. K. Halder, E. S. Gurley, A. Naheed, S. K. Saha, W. A. Brooks, S. E. Arifeen, et al., "Causes of early childhood deaths in urban Dhaka, Bangladesh,” PLoS One, vol. 4(12), pp. e8148, 2009.

[7] National Institute of Population Research and Training (NIPORT), Bangladesh Demographic and Health Survey 2007, Calverton, USA: Macro International, 2009.

[8] T. Ahmed and A. M. S. Ahmed, "Reducing the burden of malnutrition in Bangladesh," British Med. J., vol. 339, pp. b4490, 2009.

[9] I. Rudan, L. Tomaskovic, C. Boschi-Pinto and H. Campbell, "Global estimate of the incidence of clinical pneumonia among children under five years of age," Bull. World Health Organ., vol. 82, pp. 895-903, 2004.

[10] United Nations Population Division, "World population prospects: population database," 2006. Available from: http://esa.un.org/unpp [accessed on 10 July 2013].

[11] O. Ruuskanen, E. Lahti, L. C. Jennings and D. R. Murdoch, "Viral pneumonia," Lancet, vol. 377 (9773), pp. 1264-1275, 2011.

[12] V. Singh and S. Aneja, "Pneumonia - management in the developing world," Paediat. Res. Rev., vol. 12 (1), pp. 52-59, 2011.

[13] L. Liu, H. L. Johnson, S. Cousens, J. Perin, S. Scott, J. E. Lawn, I. Rudan, et al., "Global, regional, and national causes of child mortality: an updated systematic analysis for 2010 with time trends since 2000," Lancet, vol. 379(9832): 2151-2161, 2012.

[14] I. Rudan, C. Boschi-Pinto, Z. Biloglav, K. Mulholl and H. Campbell, "A global action plan for the prevention and control of pneumonia," Bull. World Health Organ., vol. 86 (5), pp. 408-416, 2008.

[15] R. Lodha, S. K. Kabra and R. M. Pandey, "Antibiotics for community-acquired pneumonia in children," Cochrane Database Syst Rev, vol. 6, pp. CD004874. doi: 10.1002/14651858.CD004874.pub4 
[16] M. Garenne, C. Ronsmans and H. Campbell, "The magnitude of mortality from acute respiratory infections in children under 5 years in developing countries," World Health Stat., vol. 45(2-3), pp. 180-191, 1992.

[17] World Health Organization (WHO), "Pneumococcal vaccines," Wikly. Epidemiol. Rec., vol. 74 (23): 177-183, 1999.

[18] National Institute of Population Research and Training (NIPORT), Bangladesh Demographic and Health Survey, Calverton, USA: Macro International, 2005.

[19] W. A. Brooks, M. Santosham and A. Naheed, "Effect of weekly zinc supplements on incidence of pneumonia and diarrhoea in children younger than 2 years in an urban, low-income population in Bangladesh: randomised controlled trial,” Lancet, vol. 366, pp. 999-1004, 2005.

[20] K. Zaman, A. H. Baqui, M. Yunus, "Acute respiratory infections in children: a community-based longitudinal study in rural Bangladesh," J Trop. Pediatr, vol. 43, pp. 133-137, 1997.

[21] L. A. Mandell, R. G. Wunderink and A. Anzueto, "Infectious Diseases Society of America/American Thoracic Society consensus guidelines on the management of community acquired pneumonia in adults," Clin. Infect. Dis., vol. 44(s), pp. 27-72, 2007.

[22] H. Li, M. A. McCormac, R. W. Estes, S. E. Sefers, R. K. Dare, J. D. Chappell, et al., "Simultaneous detection and high-throughput identification of a panel of RNA viruses causing respiratory tract infections," J. Clin. Microbiol., vol. 45, pp. 2105-2109, 2007.

[23] A. C. van de Pol, A. M. van Loon, T. F. Wolfs, N. J. Jansen, M. Nijhuis, E. K. Breteler, R. Schuurman and J. W. Rossen, "Increased detection of respiratory syncytial virus, influenza viruses, parainfluenza viruses, and adenoviruses with real-time PCR in samples from patients with respiratory symptoms," J. Clin. Microbiol., vol. 45, pp. 2260-2262, 2007.

[24] L. Bonzel, T. Tenenbaum, H. Schroten, O. Schildgen, S. Schweitzer-Krantz and O. Adams, "Frequent detection of viral coinfection in children hospitalized with acute respiratory tract infection using a real-time polymerase chain reaction,” Pediat. Infect. Dis. J., vol. 27, pp. 589-594, 2008.

[25] A. R. Falsey, M. C. Criddle and E. E. Walsh, "Detection of respiratory syncytial virus and human metapneumovirus by reverse transcription polymerase chain reaction in adults with and without respiratory illness," J. Clin. Virol., 2006, vol. 35, $46-50$.

[26] K. J. Henrickson and C. B. Hall, "Diagnostic assays for respiratory syncytial virus disease,” Pediat. Infect. Dis. J., vol 26(11), pp. S36-S40, 2007.

[27] K. Smith, M. A. Diggle and S. C. Clarke, "Automation of a fluorescence based multiplex PCR for the laboratory confirmation of common bacterial pathogens," J. Med. Microbiol., vol. 53, pp. 115 -117, 2004.

[28] A. McLuckie, Respiratory disease and its management, New York: Springer, 2009, pp. 51.

[29] J. C. Pommerville, Alcamo's Fundamentals of Microbiology, Ninth ed., Sudbury: Jones \& Bartlett, 2010, pp. 323.

[30] O. L. Ebby, "Community-acquired pneumonia: from common pathogens to emerging resistance," Emer. Med. Prac., vol. 7(12), pp. 1-24, 2005

[31] R. Noor, S. Akhter, F. Rahman, S. K. Munshi, S. M. Mostafa Kamal and F. Feroz, "Frequency of extensively drug resistant tuberculosis (XDR-TB) among re-treatment cases in NIDCH, Dhaka, Bangladesh,” J. Infect. Chemother., vol. 19(2), pp. $243-248,2013$.

[32] S. A. Khan, F. Feroz, R. Noor, "Study of extended spectrum $\beta$-lactamase producing bacteria from urinary tract infection in Dhaka city, Bangladesh," Tzu Chi Med. J., vol. 25(1), pp. 39-42, 2013.

[33] R. Noor, S. R. Shaha, F. Rahman, S. K. Munshi, M. A. Uddin and M. M. Rahman. "Frequency of opportunistic and other intestinal parasitic infections among the HIV infected patients in Bangladesh," Tzu Chi Med. J., vol. 24(4), pp. 191-195, 2012.

[34] D. Lieberman, A. Shimoni, E. Shleyfer, H. Castel, A. Terry, I. Harman-Boehm, N. Peled, D. Lieberman."Nasopharyngeal versus Oropharyngeal Sampling for Isolation of Potential Respiratory Pathogens in Adults," Diagn Microbiol Infect Dis.; vol. 58(2), pp. 147-51, 2007.

[35] N. Johansson, M. Kalin, C. G. Giske, J. Hedlund. "Diagn Quantitative detection of Streptococcus pneumoniae from sputum samples with real-time quantitative polymerase chain reaction for etiologic diagnosis of community-acquired pneumonia," Microbiol Infect Dis., vol. 60(3), pp.:255-61, 2008. 